\title{
PEMODELAN KNOWLEDGE MANAGEMEN PENGUATAN KARAKTER KERJA SISWA SMK PADA INDUSTRI BERBASIS WEB
}

\author{
Suwarto ${ }^{1}$, Dedy Prasetya Kristiadi ${ }^{2}$,Putri Rahayu ${ }^{3}$ \\ ${ }^{1}$ Dosen STMIK Raharja Jurusan Sistem Informasi, ${ }^{2}$ Dosen STMIK Raharja Jurusan Sistem \\ Komputer, ${ }^{3}$ Mahasiswa STMIK Raharja Jurusan Sistem Informasi \\ 1,2,3 Jl.Jendral Sudirman No.40, Modern Cikokol, Tangerang \\ e-mail: ${ }^{1}$ suwarto@raharja.info, ${ }^{2}$ dedy.prasetya@raharja.info, ${ }^{3}$ putri.rahayu@raharja.info
}

\begin{abstract}
Abstraksi
Penelitian ini bertujuan untuk meningkatkan karakter kerja berbasis industry bagi siswa smk dengan metode knowledge management. Knowledge management adalah manajemen suatu organisasi dengan fokus khusus terhadap knowledge. Penerapan knowledge management dengan menitikberatkan pada penguatan karakter kerja berbasis industry menggunakan web, diharapkan dapat menjadi solusi dari kebutuhan pendidikan karakter bagi para siswa di sekolah menengah kejuruan untuk diterima bekerja sesuai bidangnya. Penelitian ini akan mengembangkan model knowledge management system dan merancang prototype dari model yang dikembangkan pada karakter kerja industry untuk dishare kepada para guru. Metodologi yang digunakan adalah dengan melakukan analisis faktor kontingensi untuk mendapatkan model knowledge management system tersebut. Model knowledge management system yang dihasilkan mendukung proses Sosialisasi, Eksternalisasi, Kombinasi, Internalisasi (SECI).
\end{abstract}

Kata Kunci : Knowledge management,penguatan karakter kerja,SMK

\section{ABSTRACTION}

This study aims to improve the character of industry-based work for vocational school with knowledge management methods. Knowledge management is an attempt to increase the knowledge that is useful in the team at the organization. Knowledge management is the management of an organization with a special focus on knowledge. Implementation of knowledge management with emphasis on strengthening the character of industry-based work using the web, is expected to be a solution of the character education needs for students in vocational high schools to be accepted to work according to their fields. This research will develop the model of knowledge management system and design prototype of model developed on the character of industry work to be shared to the teachers. The methodology used is to perform contingency factor analysis to get the knowledge management system model. The resulting knowledge management system model supports the Socialization, Externalization, Combination, Internalization (SECI) process.

Keywords: Knowledge management, strengthening work character, Vocational school 
Perkembangan tehnologi informasi dan komunikasi yang semakin pesat mendukung adanya pertumbuhan bisnis dengan kebutuhan sumberdaya manusia yang sangat tinggi. Hal ini mengindikasikan bertambahnya permintaan sumber daya yang sesuai dengan yang diharapkan oleh industry yang membutuhkan. Sekolah kejuruan adalah institusi pendidikan menengah yang menyediakan lulusan kerja sebagai sumber daya manusia dalam dunia industri. Dalam menjalankan proses belajarnya institusi ini melakukan pelatihan kerja dan teori kerja yang dibutuhkan oleh industri. Sejalan dengan PP no.29 tahun 1990 pasal 3 ayat 2 dinyatakan bahwa pendidikan menengah kejuruan mengutamakan penyiapkan siswa untuk memasuki lapangan kerja serta mengembangkan sikap profesionalitas. Sedangkan menurut UU RI no.20 th.2003 tentang sistem pendidikan nasional pasal 18 adalah : Pendidikan Kejuruan merupakan pendidikan menengah yang mempersiapkan peserta didik terutama untuuk bekerja pada bidang tertentu [1]. Pembinaan karakter kerja berbasis industri pada lulusan sekolah kejuruan adalah salah satu fator penunjang keterserapan lulusan. Pembinaan karakter terdiri dari pembangun rasa percaya diri, bertanggung jawab terhadap pekerjaan yang sedang dilakukan sampai tuntas; berdisiplin dengan waktu, memiliki daya juang yang tinggi. Knowledge sharing adalah model yang dapat digunakan oleh institusi pendidikan kejuruan untuk membantu mendapatkan informasi tentang karakter yang dibutuhkan dalam dunia kerja sekaligus alat untuk membantu menyelaraskan kebijakan sekolah dengan tuntutan karakter dalam dunia industry.

\subsection{Tujuan Penelitian}

Tujuan utama yang ingin dicapai dalam penelitian ini adalah (1) Bagaimana mengidentifikasi knowledge management berkaitan karakter kerja yang diharapkan oleh industry ? (2)Bagaimana pengembangan model knowledge management system dan prototype knowledge management system yang sesuai bagi para guru yang berbasis web ?.

\subsection{Manfaat}

1. Manfaat dari penelitian ini adalah membangun suatu knowledge management system berbasis web sebagai sarana knowledge sharing yang diharapkan dapat membantu para penyelenggara pendidikan untuk mengatasi permasalahan yang ada khususnya pengembangan karakter kerja pada industri.

\subsection{Pengertian Knowledge}

\section{METODE PENELITIAN}

Knowledge didefinisikan sebagai campuran dari pengalaman, nilai, informasi kontektual, pandangan pakar dan intuisi mendasar yang memberikan suatu lingkungan dan kerangka untuk mengevaluasi dan menyatukan pengalaman baru dengan informasi[2]. Rutinitas,proses,praktek dan norma kerja perusahaan menjadi titik kajian knowledge disamping dokumentasi pada perusahaan.[3]. Knowledge dibagi menjadi dua jenis yaitu Explicit knowledge dan Tacit Knowledge, yang dapat dijabarkan sebagai berikut :

1. Explicit Knowledge merupakan pengetahuan yang dapat ditemukan secara fisik, mudah dikomunikasikan dan mudah dipelajari orang lain. 2.Tacit Knowledge dapat berupa Pengalaman seseorang, percakapan antar individu, dialog, diskusi formal maupun informal, intelegensia individu, mekanisme pengambilan keputusan, pemikiran-pemikiran. Tacit knowledge dapat juga diartikan Declarative knowledge yang menceritakan keterkaitan atau hubungan antara beberapa variable .

\subsection{Pengertian Knowledge Management}

Knowledge management adalah proses-proses organisasi yang meliputi proses identifikasi knowledge asset yang ada di organisasi, merefleksikan apa saja yang diketahui dan tidak diketahui organisasi, membagi knowledge kepada yang membutuhkan[4]. Pengelolaan asset pengetahuan yang dimiliki organisasi baik yang berada di SDM (tacit) ataupun document (explicit) agar pengetahuan tersebut dapat bernilai bagi penggunanya dalam melakukan tugas pada organisasi. Dengan knowledge management ini memungkinkan terjadinya pembuatan, komunikasi, dan pengaplikasiannya berbagai pengetahuan untuk mencapai tujuan organisasi 5]. Knowledge juga dapat diartikan sebagai kegiatan atau aktifitas untuk menciptakan, menangkap, menyebarkan, dan menggunakan knowledge agar dapat dipakai untuk pencapaian tujuan 
organisasi [6]. Berdasar beberapa definisi diatas, maka dapat disimpulkan bahwa knowledge management mempunyai arti yang sama yaitu merupakan kegiatan untuk mengelola knowledge dalam mengupayakan kemajuan pada organisasi.

\subsection{Daur Knowledge Management}

Knowledge Management memiliki 4 tahapan dengan nama SECI yaitu : 1.Socialization (Sosialisasi) adalah tahap pemindahan pengetahuan yang berbentuk tacit ke orang lain. 2.Externalization (Eksternalisasi) adalah interpretasi pengetahuan yang ada di pemikiran orang menjadi sebuah bentuk umum yang mudah dimengerti oleh orang lain..3.Determination Combination (Kombinasi) Pengetahuan yang berbentuk explicit dibagi pada orang lain dan memungkinkan semakin baiknya pengetahuan ini dengan adanya masukan dari orang lain. 4. Internalization (Internalisasi) Pengetahuan yang telah terdokumentasi dapat diambil dan digunakan oleh orang lain untuk menambah pengetahuannya [7]. Ketika orang lain mendapat pengetahuan itu maka pengetahuan tersebut dinamakan tacit.

\subsection{Karakter}

"Pendidikan karakter adalah suatu penanaman nilai-nilai perilaku (karakter) kepada warga sekolah atau kampus yang meliputi kompenen pengetahuan, kesadaran atau kemauan dan tindakan untuk melaksanakan nilai-nilai tersebut [8]. Karakter merupakan nilai-nilai yang hidup dalam diri seseorang yang dibentuk melalui proses; pendidikan, pengalaman, percobaan, pengorbanan dan pengaruh lingkungan, menjadi nilai intrinsik yang melandasi sikap dan perilaku seseorang [4]. Kriteria pendidikan kejuruan yang berhasil diantaranya: (a) persamaan alat pelatihan dan cara penggunaan alat seperti yang diperlukan dalam pekerjaan itu; (b) efektif jika melatih kebiasaan berpikir dan bekerja seperti di DU-DI; (c) efektif jika membentuk kebiasaan kerja dan kebiasaan berfikir yang benar; dan (d) perhatian pada permintaan pasar[8]. Pendidikan kejuruan memiliki tujuan utamanya yaitu menyiapkan lulusannya untuk bekerja, maka pendekatan demand driven atau pendidikan yang berbasis permintaan ini telah cukup bukti efektif dan efisien untuk dilaksanakan. Melalui pengalaman empirik, kajian teori, dan observasi, maka strategi yang digunakan adalah dengan mengadopsi sistem kerja di industri dalam pembelajaran praktik di SMK.

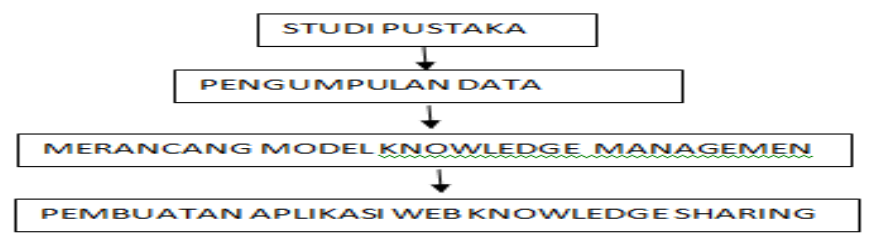

Gbr. 2.1 Mekanisme Penelitian

\subsection{Studi Pendahuluan}

Studi pendahuluan yang sudah dilakukan oleh peneliti sebelumnya adalah naskah akademik kajian kebijakan kurikulum smk oleh pusat kurikulum badan penelitian dan pengembangan departemen pendidikan nasional 2007. 


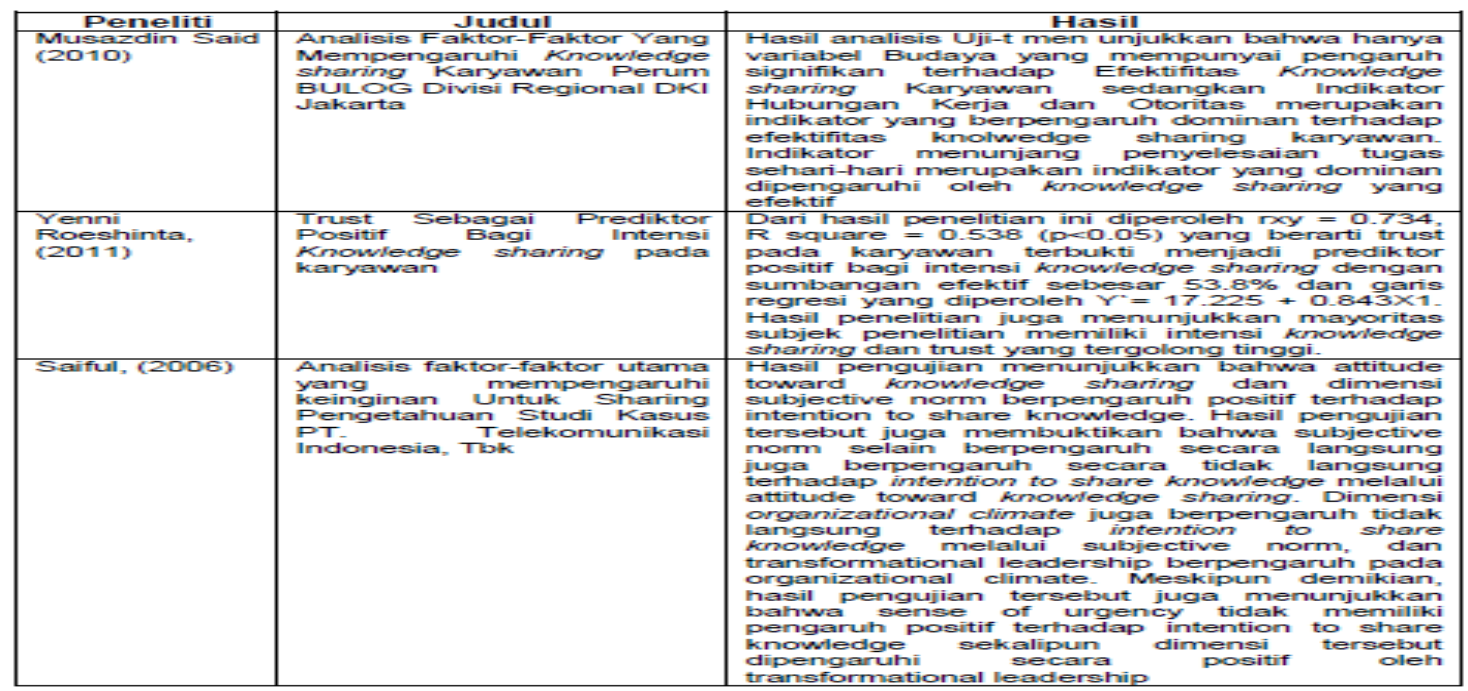

3.Hasil Dan Pembahasan

\subsection{Metode Pengumpulan Data}

Tahap 1 Penulis mengumpulkan data penelitian dengan wawancara dilakukan kepada siswa prakerin meliputi Hardskill dan softskill. Berikutnya wawancara dengan Guru berkaitan tentang materi bekal prakerin dan hasil prakerin berupa laporan. Tahap 2 Wawancara dan observasi di industry mitra sebagai tempat pelatihan kerja untuk mengetahui standar kompetensi permintaan tenaga kerja berdasar kebutuhan. Tahap 3 Pembuatan framework dan aplikasi web guna mensharing hasil temuan kepada team pengajar agar dapat menyusun standar kurikulum berbasis industry pada sekolah. Strategi kegiatan penelitian ini akan dilakukan dengan mekanisme seperti terlihat dalam struktur diagram berikut

\subsection{Analisis Karakteristik Organisasi}

Hasil analisa menunjukkan beberapa kesimpulan di antaranya :

a. Ukuran Organisasi,Jumlah siswa yang mengikuti prakerin adalah 234 siswa dengan guru pendamping sebanyak 25 orang. Pembinaan yang akan dilakukan pada peserta didik termasuk kedalam jenis organisasi yang kecil atau small[9]1.

b. Strategi bisnis dari sekolah kejuruan ini mengacu pada visi dan misi dan tujuan organisasi. Tujuan utama organisasi ini adalah mencetak manusia yang unggul dalam intelektual dan terampil serta terpuji dalam moral

c. Environment Uncertainty, Sekolah menengah kejuruan ini memiliki struktur organisasi yang jelas dan tingkat environmental uncertainty pada sekolah keuruan bersifat rendah atau low

\subsection{Analisis Karakteristik Knowledge Organisasi}

Analisa terhadap knowledge pada sekolah menengah kejuruan ini adalah bentuk pendidikan karakter yang ada. Metode yang digunakan adalah dengan melakukan wawancara dan membaca tupoksi. Analisis knowledge ini akan melihat karakteristik knowledge yang bersifat tacit, explicit, procedural dan declarative [10]. Tacit knowledge yang ada pada sekolah ini adalah berupa laporan pengalaman selama mengikuti praktek kerja industry dan solusi permasalahan yang diberikan guru pendamping. Sedangkan explicit knowledge yang ada di sekolah kejuruan ini berupa data, informasi dan dokumen baik yang belum maupun yang sudah terdokumentasi secara elektronik, misalnya dokumen materi kerja.

\subsection{Analisis proses KM yang sudah ada di organisasi}

Analisa terhadap proses-proses knowledge management yang sudah ada di Sekolah menengah kejuruan. Hasil dari analisa ini berupa existing KM process. Kemudian akan dibandingkan dengan hasil dari analisis faktor kontigensi. Analisa ini dilakukan melalui proses wawancara yang 
dilakukan dengan pihak guru dan siswa prakerin. Dengan adanya komunikasi antar para pengajar melalui diskusi maka sudah terjadi perpindahan tacit knowledge ke dalam bentuk tacit knowledge.

\subsection{Kebutuhan Fungsional Knowledge Management System}

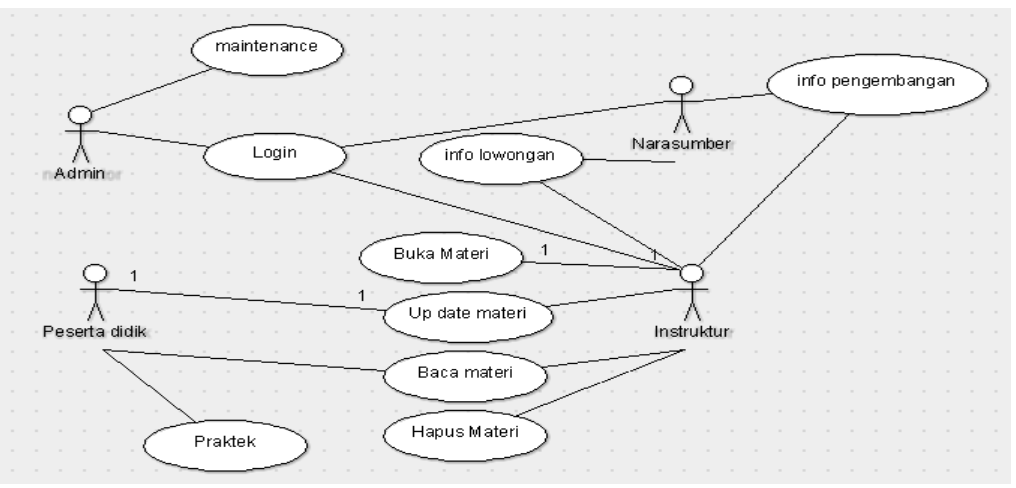

Gbr. 3.1 Use Case Diagram

Activity Diagram

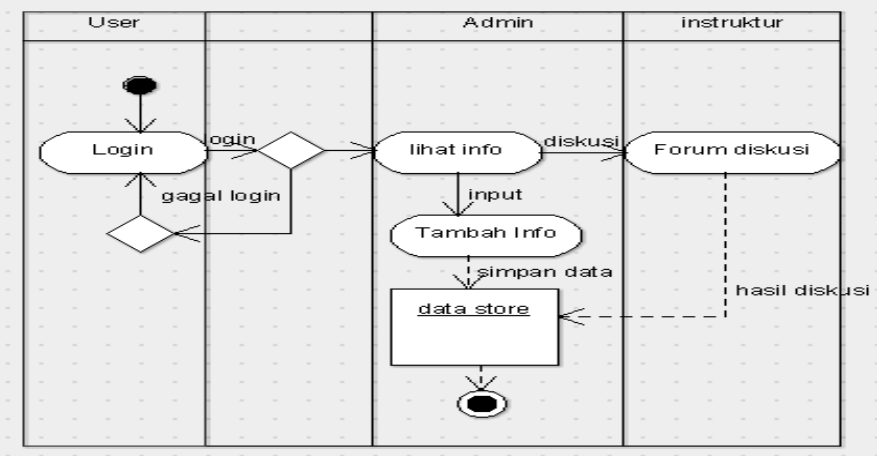

Gbr.3.2 Activity Diagram

3.6 Rancangan Arsitektur Model KMS

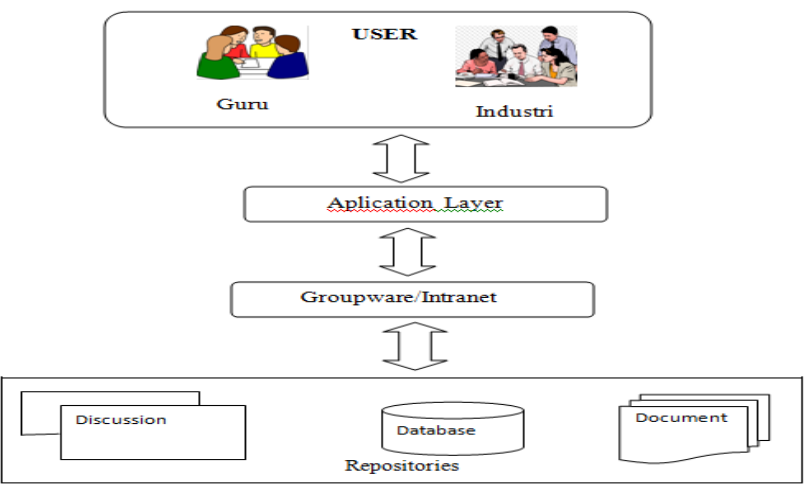

Gbr. 3.3 Rancangan Arsitektur Model KMS 
3.7 Prototipe Tampilan Knowledge managemen

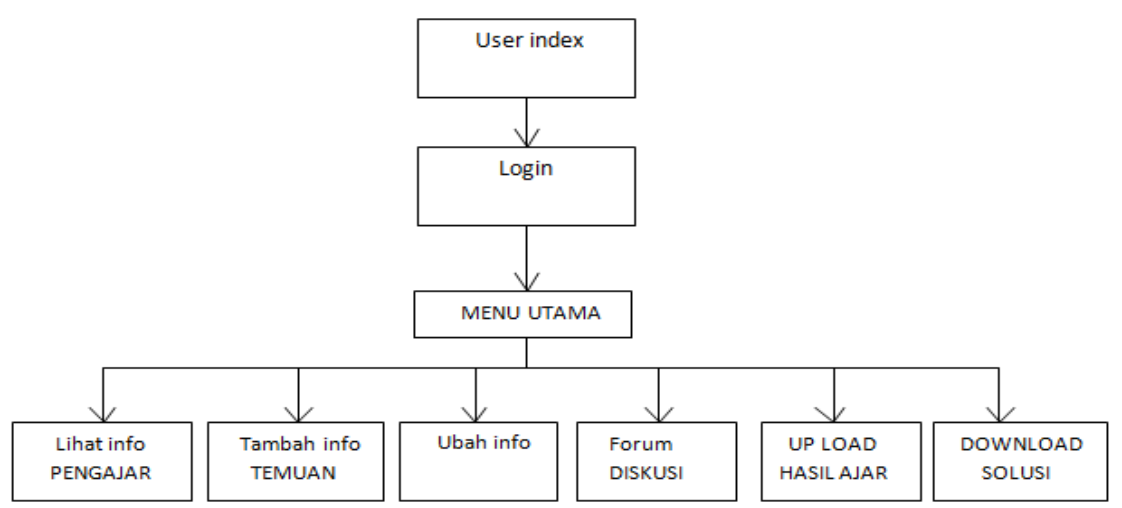

Gbr. 3.4 Prototipe Tampilan navigasi User

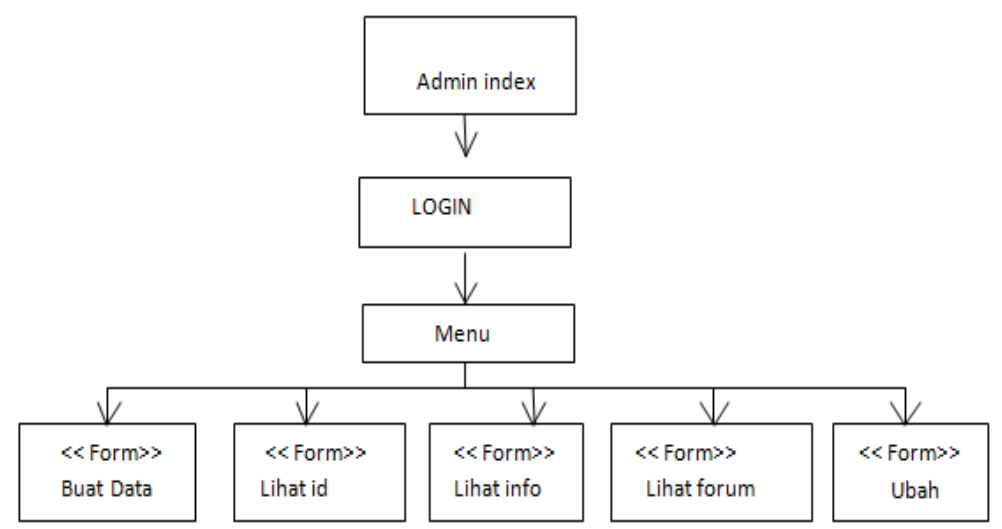

Gbr.3.5 Prototipe tampilan navigasi Admin

\subsection{Rancangan Tampilan}

\section{a. Menu Registrasi}

Menu Registrasi digunakan untuk mendaftar sebagai pengguna aplikasi.

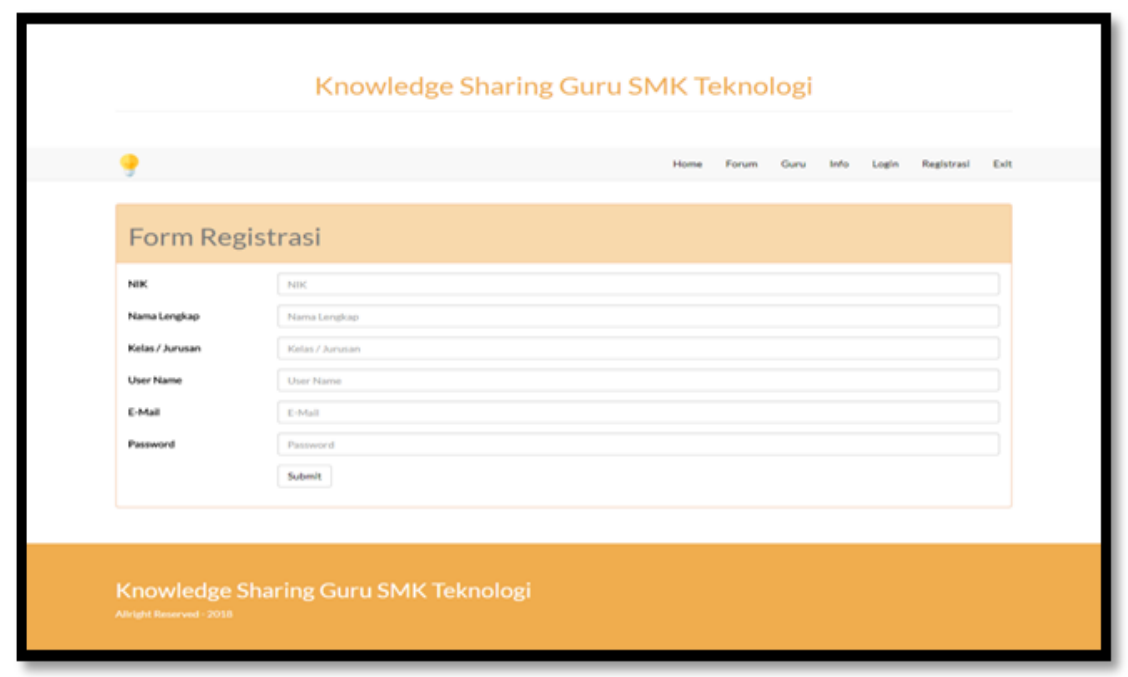

Gbr.3.6 Menu Registrasi 


\section{b. Menu Login}

Menu login digunakan untuk masuk dalam anggota pengguna yang memiliki hak untuk menggunakan fasilitas web sesuai kapasitasnya.

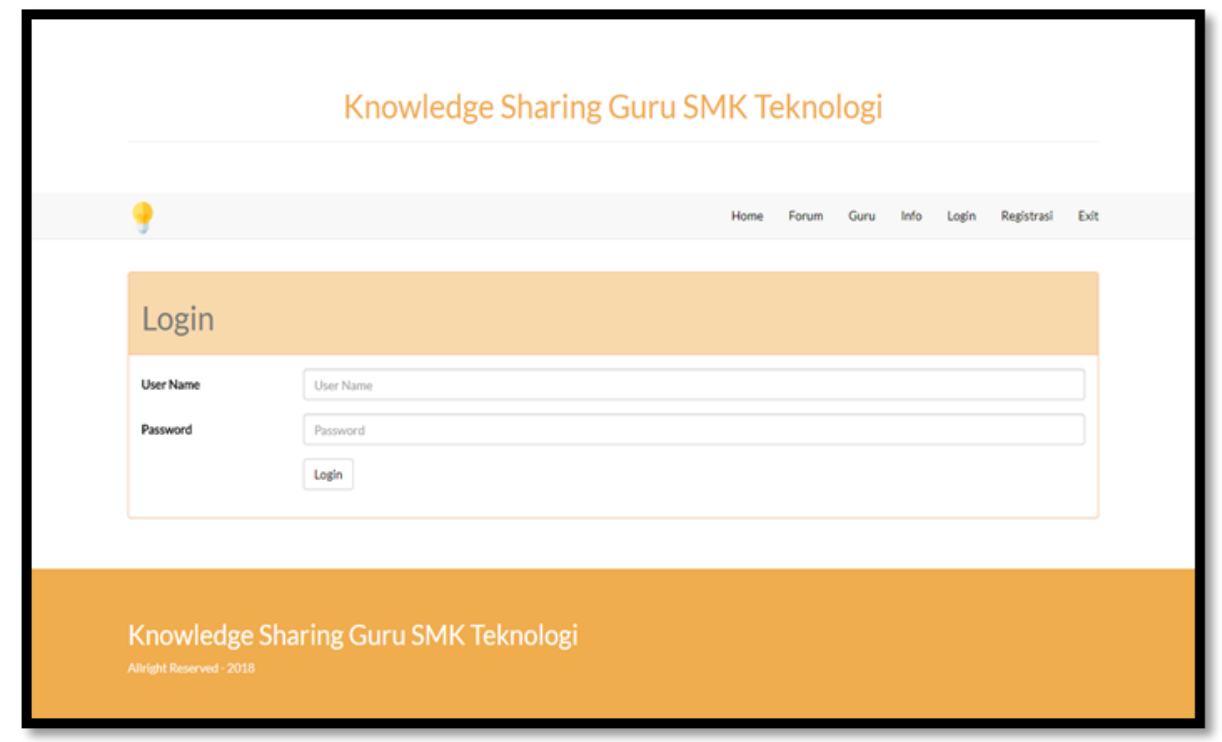

\section{Gbr.3.7 Menu Login}

\section{c. Menu Input Temuan}

Menu Input temuan digunakan oleh guru untuk memberikan masukan tentang hal-hal yang ditemukan dalam kaitannya dengan pengembangan karakter.

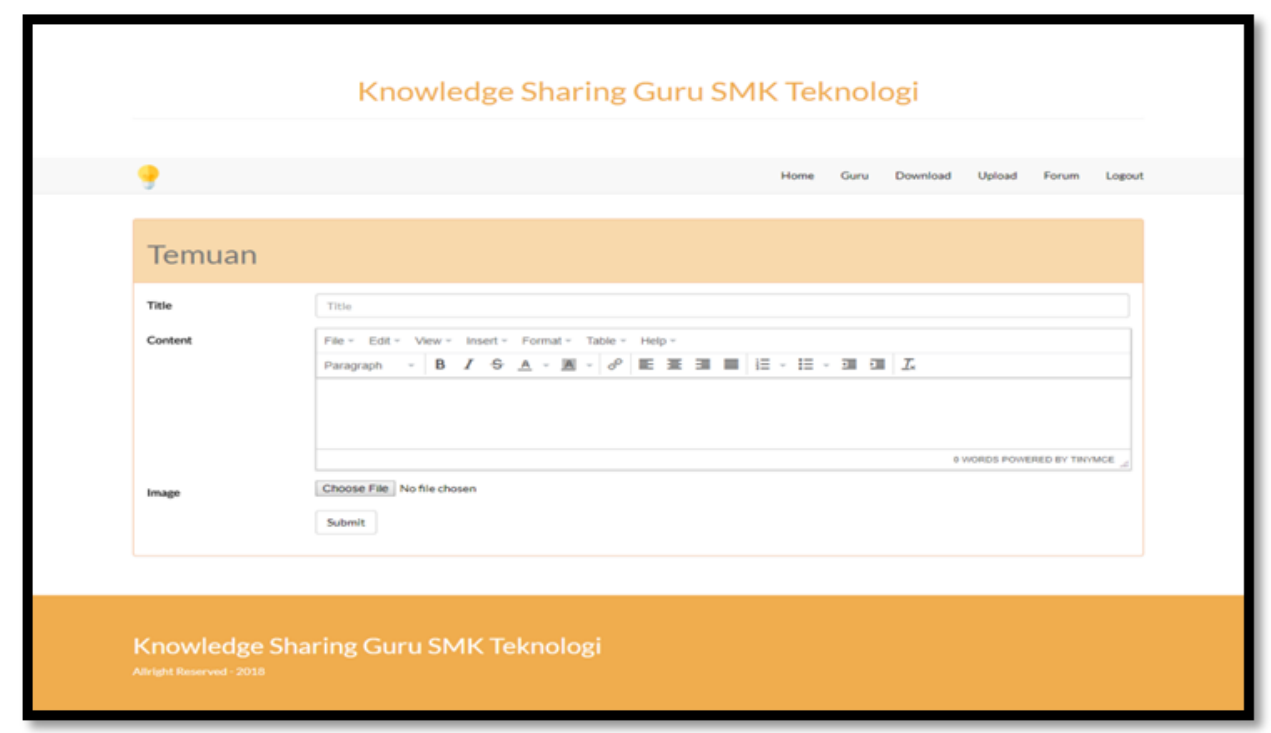

Gbr.3.8 Menu Input Temuan 


\section{d. Menu Download Temuan}

Adalah menu pengambilan data temuan untuk ditindaklanjuti dalam forum. Data temuan dapat didownload untuk dipelajari oleh team guru sebelum menghasilkan kesepakatan atau solusi.

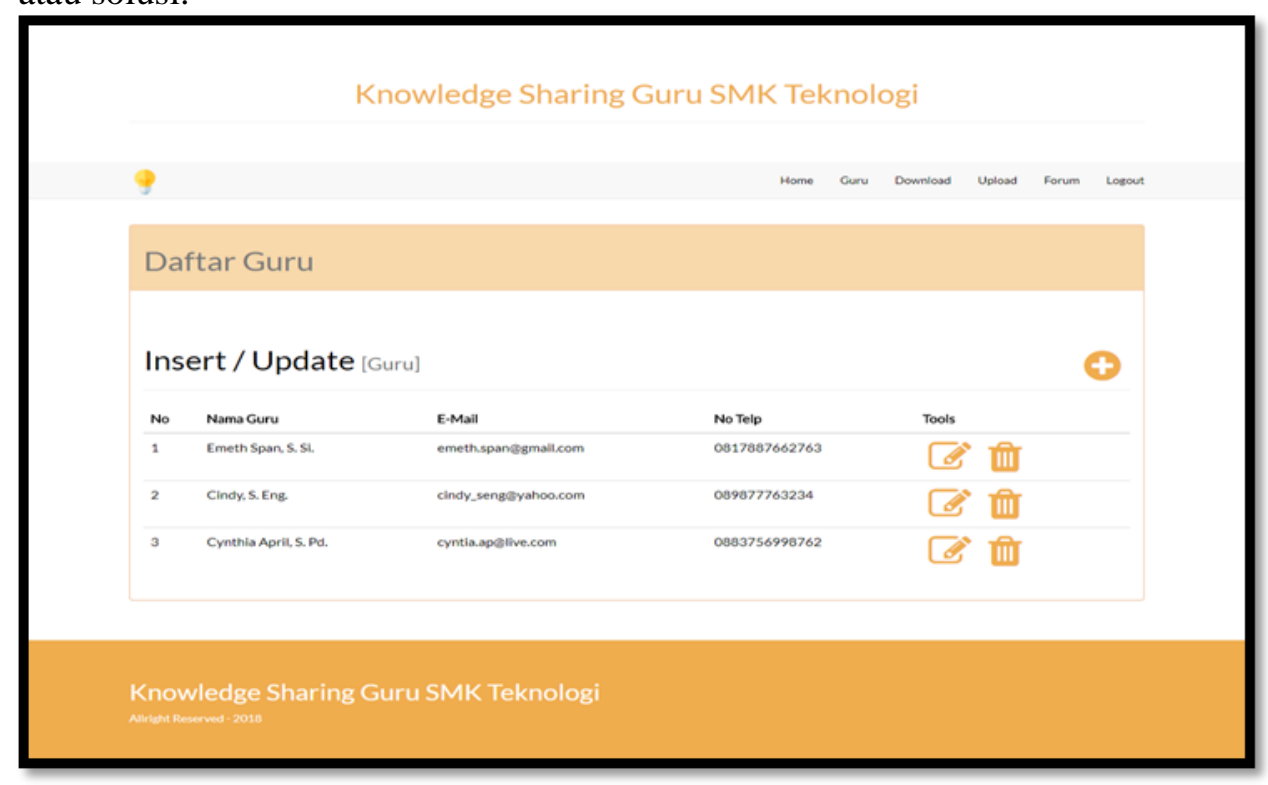

Gbr.3.9 Menu download Temuan

\section{e. Menu Forum}

Adalah menu diskusi antar guru berdasar hasil temuan yang ditanggapi oleh para guru.

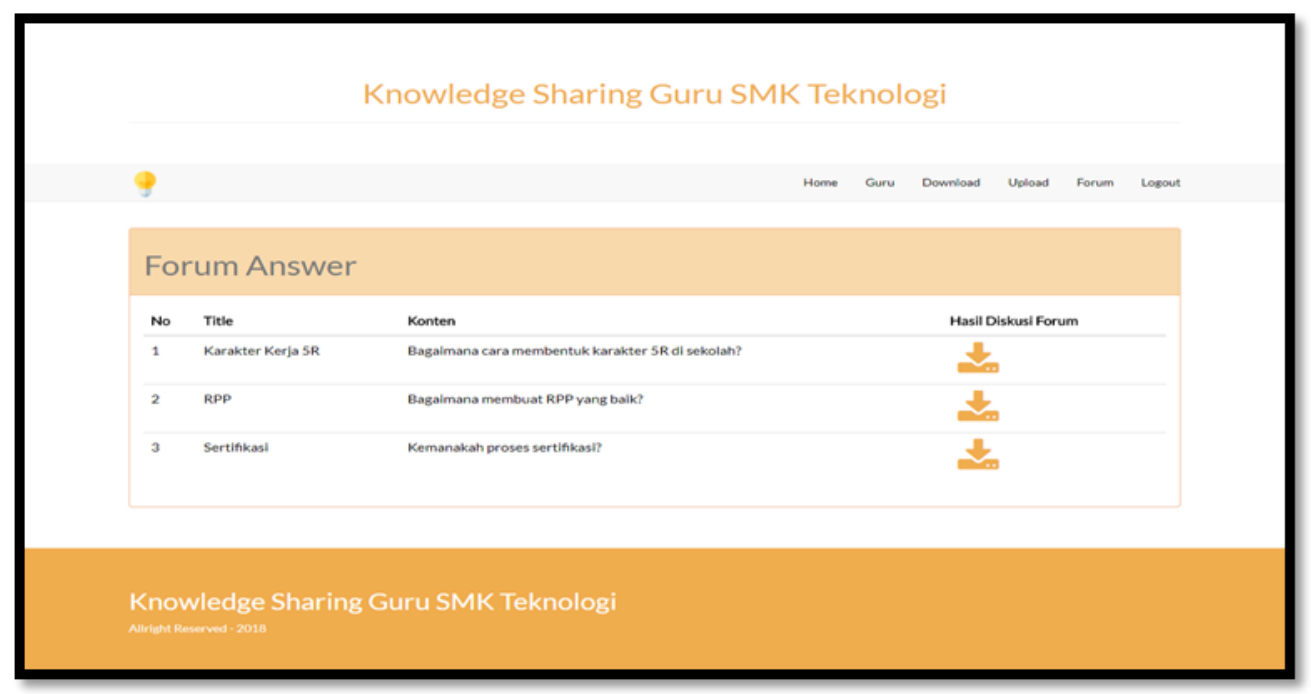

Gbr. 3.10 Forum Diskusi

\section{KESIMPULAN}

Berdasar penelitian, Knowledge Management (Knowledge Sharing) berbasis Web SMK, industri dapat menjadi narasumber pengembangan karakter yang dapat di infokan kepada guru untuk ditransfer antar guru dan peserta didik. Penerapan knowledge sharring berbasis web adalah salah satu bentuk peningkatan kualitas instruktur dalam memberikan materi yang up to date. Knowledge sharing juga mampu memberikan manfaat berupa kedekatan antara stakeholder dan organisasi yang saling menguntungkan. Dengan adanya knowledge sharing maka sumber daya 
manusia yang berkualitas pada sekolah kejuruan dapat disalurkan pada industry yang membutuhkan.

\section{SARAN}

Dari alasan di atas maka SMK perlu menerapkan knowledge managament system berbasis Web ke arah yang lebih baik. Transfer knowledge antar guru atau instruktur harus menjadi budaya bagi organisasi agar tidak tertinggal dalam hal inovasi dan kesamaan misi dalam strategi pengembangan. Transfer knowledge bagi instruktur juga akan menghasilkan kualitas yang baik bagi instruktur dan peserta didik. Dengan adanya peningkatan kualitas tersebut maka diharapkan mampu memberikan kontribusi yang besar bagi pengembangan karakter kerja pada industri. 


\section{DAFTAR PUSTAKA}

[1] Departemen Pendidikan Nasional. 2003. Undang-Undang Republik Indonesia No. 20 Tahun 2003 tentang Sistem Pendidikan Nasional. Jakarta

[2] Honeycutt, J. (2005). Knowledge Management Strategies. New Jersey: Prentice-Hall

[3] Dhote, Prajakta C., and Chandrakant N. Dhote., " Application Of Knowledge Management in Education Industry", International Journal of Information Technology and Knowledge Management, January-June 2012, Volume 5, No. 1, pp. 37-39, 2012.

[4] Dharma Kesuma, Cepi Triatna, Johar Permana. 2011. Pendidikan Karakter Kajian Teori dan Praktik. Bandung: PT Remaja Rosdakarya

[5] Thomas D. 2010. Working Knowledge: How Organizations Manage What They Know. Boston:Harvard Business School Press

[6] Beccera F. 2004. Knowledge Management : Challenges, Solutions and Technologies. Prentice Hall

[7] Carl D. 2003. Knowledge Management An Introduction to createing competitive advantage from intellectual capital. New Delhi: Vision Book.

[8] Masnur Muslich.2011. Pendidikan Karakter Menjawab Tantangan Krisis Multidimensional. Jakarta: Sinar Grafika Offset

[9] Davenport, T.H., Prusak, L. (1998). Working Knowledge: How organizations manage that they know, Harvard Busi-ness School Press, Boston, MA.

[10] Kansal, Daisy, and Deepak Sengar, “ Knowledge Management with Information Technology”, International Journal of Information Technology and Knowledge Management, January-Jue 2011, Volume 4, No. 1, pp 201-204, 2011 